Article

\title{
Body Weight as a Determining Factor in the Predominance of Adverse Drug Reactions Induced by Fixed-Dose Adalimumab Injections in Female Patients in a Korean Hospital Setting
}

\author{
Kwi Suk Kim ${ }^{1}$, Young Hee Choi ${ }^{2}{ }^{\mathbb{D}}$, Aree Moon ${ }^{3}$ and Sang Geon Kim ${ }^{1,4, *}$ \\ 1 Department of Pharmacy, Seoul National University Hospital, Seoul 03080, Korea; ag0902@hanmail.net \\ 2 College of Pharmacy, Dongguk University Seoul, Goyang-si, Gyeonggi-do 10326, Korea; \\ choiyh@dongguk.edu \\ 3 Duksung Innovative Drug Center, College of Pharmacy, Duksung Women's University, Seoul 01369, Korea; \\ armoon@duksung.ac.kr \\ 4 College of Pharmacy and Research Institute of Pharmaceutical Sciences, Seoul National University, \\ 1 Gwanak-ro, Gwanak-gu, Seoul 08826, Korea \\ * Correspondence: sgk@snu.ac.kr; Tel.: +82-2-880-7840
}

Received: 10 January 2020; Accepted: 3 February 2020; Published: 7 February 2020

\begin{abstract}
Adalimumab is used at 40-mg dose to treat systemic inflammatory diseases. Given the impact of adverse drug reactions (ADRs), which particularly result in the discontinuation of adalimumab therapy in female patients, this study examined whether sex affects the frequency and type of ADRs induced by adalimumab. In this study, the prescription records and laboratory data of patients aged $\geq 19$ years who had been admitted to the Seoul National University Hospital $(\mathrm{SNUH})$ and prescribed adalimumab were analyzed using an electronic medical record database. The analysis revealed that female patients more frequently experienced adalimumab-induced ADRs compared with male patients ( $63.2 \%$ vs. $52.2 \%)$. The incidence of ADRs was significantly higher in female patients with ankylosing spondylitis or rheumatoid arthritis than in male patients with similar conditions ( $81.5 \%$ vs. $60.7 \%$ or $64.4 \%$ vs. $50.0 \%$, respectively). The median body weight (BW) was lower in female patients than in male patients (54.0 vs. $66.0 \mathrm{~kg}$ ). Moreover, the incidence of ADRs in patients with a BW of $<54.0 \mathrm{~kg}$ (i.e., the median female BW) was higher than for those with a BW of $\geq 54.0 \mathrm{~kg}$, in both males and females. Our results suggested that the predominance of ADRs induced by adalimumab in females was because of their relatively lower BW. This suggests the importance of $\mathrm{BW}$ as a determining factor in sex disparity of ADR occurrences.
\end{abstract}

Keywords: adalimumab; adverse drug reaction; gender; body weight; skin; infection; test abnormality

\section{Introduction}

Adalimumab binds to tumor necrosis factor (TNF)-alpha and blocks interactions with the p55 and p75 cell surface TNF receptors, inhibiting inflammatory responses. The drug is widely prescribed for both male and female patients with rheumatoid arthritis, ankylosing spondylitis, Crohn's disease, ulcerative colitis, and psoriasis [1,2], and also for patients with hidradenitis suppurativa, non-radiographic axial spondyloarthritis, peripheral spondyloarthritis, and non-infectious uveitis [3]. Adalimumab is currently marketed in injection vials and pens containing a fixed dose of $40 \mathrm{mg}$ for adults, regardless of differences in sex or body weight (BW) [4]. The common side effects of adalimumab include injection site pain, upper respiratory tract infection, increased creatine phosphokinase levels, headache, rash, sinusitis, nausea, urinary tract infection, abdominal pain, flu-like syndrome, hyperlipidemia, 
back pain, high cholesterol, hemuresis, and hypertension. The occurrences and severity of adverse drug reactions (ADRs) vary among patients treated with adalimumab [5-7]; however, the exact reasons for these variations have remained elusive.

It has been recognized that the frequent and common adalimumab-induced ADRs have resulted in a fear of such deleterious effects, leading to a decrease in drug compliance [5-8]. Indeed, there have been controversial reports of sex-dependent ADRs induced by adalimumab therapy. A small group of prospective clinical cohort studies showed that adalimumab induced more ADRs in female patients, who more often discontinued the drug owing to negative effects [8]. In another study, female sex was considered to be the strongest predictor of higher anti-TNF drug discontinuation rates $[9,10]$. Moreover, it has been reported that female sex is associated with lower trough levels of adalimumab and a higher incidence of adalimumab antibody production [11]. Additionally, a prospective, comparative, multicenter, and long-term drug-survival study has indicated that a higher body mass index (BMI) is a predictor of discontinuation of certain biological agents, including adalimumab, owing to their adverse effects or inefficacy [12,13]. Thus, female sex has been reported as a consistent predictor for drug discontinuation owing to side effects.

It has been claimed that differences between the two sexes regarding body composition, such as smaller organ sizes and higher proportion of body fat in females, may result in different pharmacokinetics of certain biological agents (e.g., rituximab and cetuximab) $[14,15]$. These differences, along with hormonal differences, suggest the requirement of sex-dependent dosage regimens. Hence, further analysis may be necessary to understand the basis of ADRs with regard to sex differences. Given the sex-skewed impact of ADRs on the discontinuation of adalimumab therapy and our preliminary analysis of spontaneous ADR incidence reports over the past decade, we aimed to examine whether there were any sex-based differences in ADRs induced in patients receiving adalimumab medications using an electronic medical record (EMR) database, in conjunction with test results and nursing records, in Seoul National University Hospital (SNUH) between 2008 and 2018. In this study, we proposed that an average BW of $54.0 \mathrm{~kg}$ was the threshold that determined ADR types and adalimumab frequencies and that the predominance of ADRs in female patients may result from the fixed-dose injection regimens administered to adults, regardless of an individual patient's BW.

\section{Experimental Section}

\subsection{EMR Data Collection}

The study was approved by the Institutional Review Board of SNUH (IRB\# H-1803-095-930), which is a 1779-bed medical center in the Republic of Korea. The records of 792 patients aged $\geq 19$ years who were admitted to SNUH and had been prescribed adalimumab at least once between February 2008 and May 2018 were extracted from the EMR database. After the records of patients with cancelled prescriptions of adalimumab $(n=65)$ were removed, 727 patient records remained. The collected data contained anonymous codes representing patient files comprising age, sex, height, initial BW, medical diagnosis codes, concomitant diseases, ADRs, dates of laboratory tests conducted and medications (generic and brand name), and prescription date and duration.

\subsection{Analysis of Prescription and Laboratory Data}

On the basis of the laboratory data, various parameters, including diseases, prescription information for adalimumab (e.g., prescription period and co-prescribed drugs), types and frequencies of ADRs, and modification of prescriptions after ADRs, were investigated.

\subsection{Statistics}

All values are presented as medians (ranges) or averages \pm standard deviations, as appropriate. The chi-square test was performed to assess any sex-based differences in the occurrence of ADRs. 
Statistical analyses were computed by using the IBM SPSS statistics 23.0 software package (SPSS Inc., Chicago, IL, USA).

\section{Results}

\subsection{Patient Information and Evaluation of Adalimumab Efficacy}

Patients who were prescribed adalimumab were divided into subgroups according to BW cutoffs and sex as shown in Figure 1. The demographic characteristics of all patients who were administered adalimumab are summarized in Table S1, which shows a significantly higher incidence of ADRs in female patients than in male patients $(60.9 \%$ vs. $50.9 \%, p<0.001)$. In our analysis, adalimumab was prescribed to patients with various conditions, such as ankylosing spondylitis (A); Bechet's disease (B); Crohn's disease $(\mathrm{C})$; Bechet's disease plus Crohn's disease $(\mathrm{B}+\mathrm{C})$; psoriasis $(\mathrm{P})$; rheumatoid arthritis (R); and comorbid diseases. Most subgroups of female patients with each of these diseases had a significantly higher incidence of ADRs than the corresponding subgroups of male patients (Table S1). The efficacy of adalimumab was comparable between both the sexes. In addition, there was a significant sex-related difference in age among the patients treated with adalimumab $(n=727)$ (Table S1): Female patients were significantly older than male patients ( 46.0 vs. 34.5 years, $p<0.001)$.

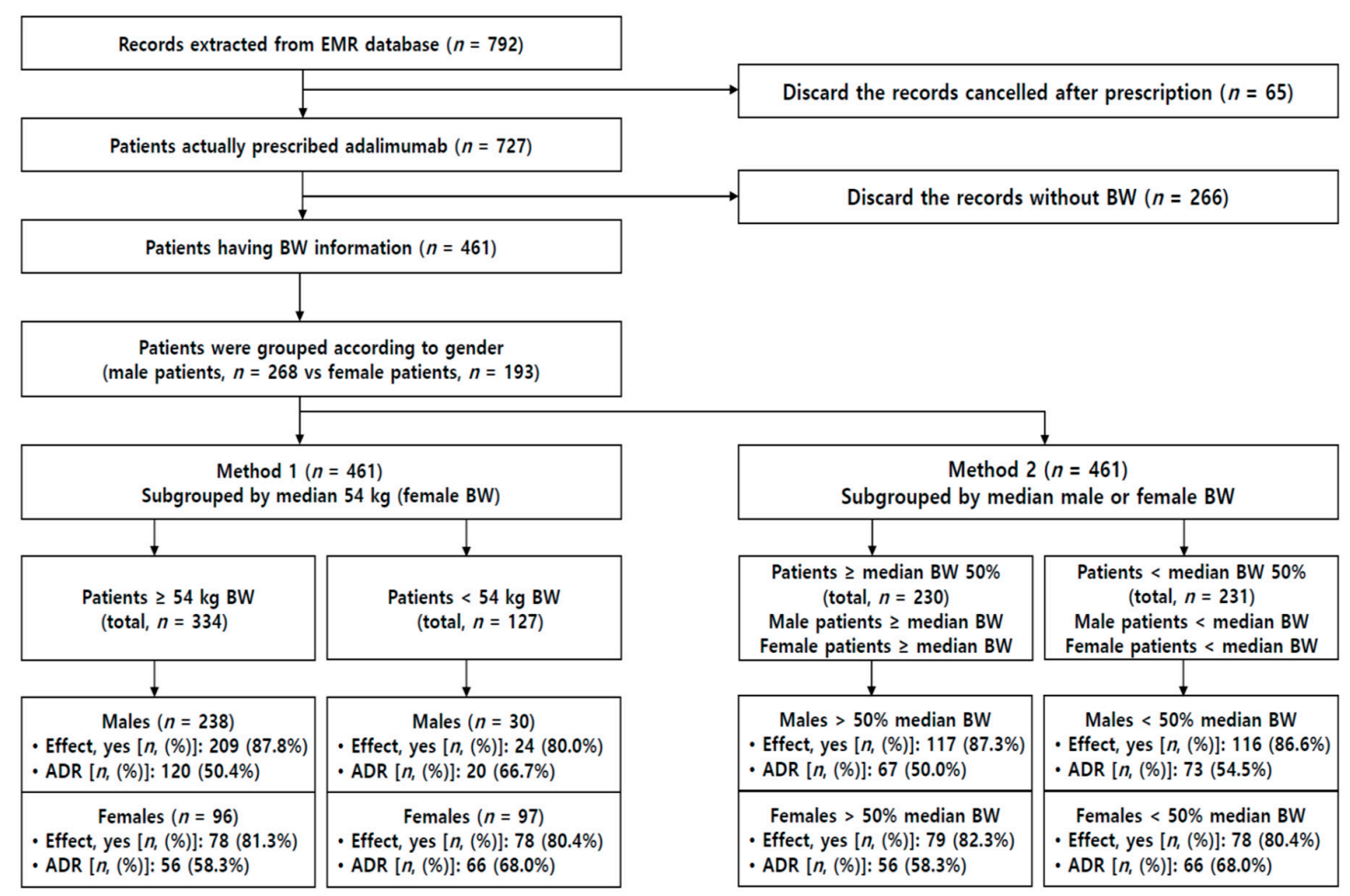

Figure 1. A flowchart showing subgrouping of patients, adverse drug reactions (ADRs), adalimumab in patients with records of body weight (BW).

The analysis of patients' BW data $(n=461)$ revealed a notable difference in mean BW between male and female patients ( 66.0 vs. $54.0 \mathrm{~kg}, p=0.038$; Table 1$)$, suggesting that $\mathrm{BW}$ is a discriminating factor. In addition, the mean age of female patients was higher than that of male patients (48.0 vs. 35.5 years, $p<0.001$ ).

Compared with female patients, male patients were more frequently treated for ankylosing spondylitis, Bechet's disease, and Crohn's disease among all conditions. Conversely, treatments for rheumatoid arthritis were more frequently administered to female patients (Table 1). The responders to adalimumab were marked as "efficient" or "improving laboratory results," whereas the non-responders were marked as "inefficient," "stopped administration," or "changed to another biologic" from the 
reviews of clinical signs or laboratory data in the EMR data files. To assess disease progression, the efficacy of adalimumab was evaluated every 3 months in accordance with the guidelines of health insurance benefits. Sex-based differences were not observed in the overall efficacy of adalimumab for the studied conditions (i.e., $86.9 \%$ in male patients vs. $83.6 \%$ in female patients) (Table 1). The subgroup analyses for the patients with different diagnoses revealed no significant differences in efficacy between the sexes (Table 1).

Table 1. The efficacy and adverse drug reactions (ADRs) of adalimumab in patients with records of body weight (BW).

\begin{tabular}{|c|c|c|c|}
\hline Categories & & & \\
\hline Total $(n=461)$ & Male $(n=268)$ & Female $(n=193)$ & $p$-Values \\
\hline Age (Median, $(\min -\max ))^{*}$ & $35.5(19-78)$ & $48(19-84)$ & $p<0.001$ \\
\hline BW $(\text { Median, }(\min -\max ))^{*}$ & $66.0(36.8-120)$ & $54.0(31.7-80.0)$ & $p=0.038$ \\
\hline \multicolumn{4}{|l|}{ Effect $(n,(\%))$} \\
\hline Yes & $233(86.9 \%)$ & $156(83.6 \%)$ & $p=0.075$ \\
\hline No * & $25(9.3 \%)$ & $32(13.5 \%)$ & $p=0.054$ \\
\hline Non-Judgment & $7(2.6 \%)$ & $5(2.9 \%)$ & $p=0.989$ \\
\hline Number of Patients with ADRs $(n,(\%)){ }^{*}$ & $140(52.2 \%)$ & $122(63.2 \%)$ & $p=0.019$ \\
\hline Number of ADRs $(n)$ & 223 & 199 & $p=0.155$ \\
\hline ADR per Patient (No. of Incidences/No. of Patients with ADR) & 1.6 & 1.6 & \\
\hline \multicolumn{4}{|l|}{ Diagnosis } \\
\hline \multicolumn{4}{|l|}{ (1) Ankylosing Spondylitis (A) } \\
\hline Total $(n=149)$ & Male $(n=122)$ & Female $(n=27)$ & \\
\hline Age (Median, (min-max)) & $36(19-78)$ & $41(19-67)$ & $p=0.401$ \\
\hline BW (Median, (min-max)) & $72.0(50.0-120.0)$ & $58.4(38.6-80.0)$ & $p=0.152$ \\
\hline Effect $(n,(\%))$ & $109(89.3 \%)$ & $22(81.5 \%)$ & $p=0.257$ \\
\hline Number of Patients with ADRs $(n,(\%)){ }^{*}$ & $74(60.7 \%)$ & $22(81.5 \%)$ & $p=0.041$ \\
\hline Number of ADRs $(n)$ & 122 & 43 & $p=0.066$ \\
\hline ADR Cases per Patient & 1.6 & 2.0 & \\
\hline \multicolumn{4}{|l|}{ (2) Rheumatoid Arthritis (R) } \\
\hline Total $(n=125)$ & Male $(n=38)$ & Female $(n=87)$ & \\
\hline Age (Median, (min-max)) & $31.5(19-78)$ & $54(19-84)$ & $p=0.194$ \\
\hline BW (Median, (min-max)) & $65.0(36.8-100.0)$ & $55.0(31.7-74.0)$ & $p=0.626$ \\
\hline Effect $(n,(\%))$ & $33(86.8 \%)$ & $67(77.0 \%)$ & $p=0.206$ \\
\hline Number of Patients with ADRs $(n,(\%))$ & $19(50.0 \%)$ & $56(64.4 \%)$ & $p=0.131$ \\
\hline Number of ADRs $(n)^{*}$ & 36 & 79 & $p=0.037$ \\
\hline ADR Cases per Patient & 1.9 & 1.4 & \\
\hline \multicolumn{4}{|l|}{ (3) Bechet's Disease Plus Crohn's Disease $(B+C)$} \\
\hline Total $(n=144)$ & Male $(n=91)$ & Female $(n=53)$ & \\
\hline Age (Median, (min-max)) & $35(19-71)$ & $36(19-75)$ & $p=0.093$ \\
\hline BW (Median, (min-max)) & $60.3(38.5-98.6)$ & $49.6(38.3-76.6)$ & $p=0.241$ \\
\hline Effect $(n,(\%))$ & $76(83.5 \%)$ & $45(84.9 \%)$ & $p=0.826$ \\
\hline Number of Patients with ADRs $(n,(\%))$ & $37(40.7 \%)$ & $30(56.6 \%)$ & $p=0.064$ \\
\hline Number of ADRs $(n)$ & 51 & 53 & $p=0.115$ \\
\hline ADR Cases per Patient & 1.4 & 1.8 & \\
\hline
\end{tabular}


Table 1. Cont.

\begin{tabular}{|c|c|c|c|}
\hline Categories & & & \\
\hline Total $(n=461)$ & Male $(n=268)$ & Female $(n=193)$ & $p$-Values \\
\hline \multicolumn{4}{|l|}{ (4) Psoriasis (P) } \\
\hline Total $(n=15)$ & Male $(n=8)$ & Female $(n=7)$ & \\
\hline Age (Median, (min-max)) & $38(25-67)$ & $58(46-64)$ & $p=0.307$ \\
\hline BW (Median, (min-max)) & $71.5(56.7-87.0)$ & $54.0(48.2-65.0)$ & $p=0.449$ \\
\hline Effect $(n,(\%))$ & $6(75.0 \%)$ & $6(85.7 \%)$ & $p=0.605$ \\
\hline Number of Patient with ADRs $(n,(\%))$ & $5(62.5 \%)$ & $5(71.4 \%)$ & $p=0.714$ \\
\hline Number of ADRs $(n)$ & 6 & 10 & $p=0.267$ \\
\hline ADR Cases per Patient & 1.2 & 2.0 & \\
\hline \multicolumn{4}{|c|}{ (5) Two or More Other Diseases (Comorbid Diseases) } \\
\hline Total $(n=17)$ & Male $(n=6)$ & Female $(n=11)$ & \\
\hline Age (Median, (min-max)) & $47(22-60)$ & 37 (19-71) & $p=0.319$ \\
\hline BW (Median, (min-max)) & $57.9(54.0-86.0)$ & $57.0(34.6-63.2)$ & $p=0.386$ \\
\hline Effect $(n,(\%))$ & $6(100.0 \%)$ & $9(81.8 \%)$ & $p=0.266$ \\
\hline Number of Patients with ADRs $(n,(\%))$ & $5(83.3 \%)$ & $7(63.6 \%)$ & $p=0.394$ \\
\hline Number of ADRs $(n)$ & 8 & 11 & $p=0.315$ \\
\hline ADR Cases per Patient & 1.6 & 1.6 & \\
\hline \multicolumn{4}{|l|}{ (6) Others (E) } \\
\hline Total $(n=11)$ & Male $(n=3)$ & Female $(n=8)$ & \\
\hline Age (Median, (min-max)) & $36(36-48)$ & $26.5(19-71)$ & $p=0.388$ \\
\hline BW [median, (min-max)) & $95.7(86.8-109.2)$ & $54.1(49.0-74.5)$ & $p=0.358$ \\
\hline Effect $(n,(\%))$ & $3(100.0 \%)$ & $7(87.5 \%)$ & $p=0.521$ \\
\hline Number of Patients with ADRs $(n,(\%))$ & $0(0.0 \%)$ & $2(25.0 \%)$ & $p=0.338$ \\
\hline Number of ADRs $(n)$ & 0 & 3 & $p=0.632$ \\
\hline ADR Cases Per Patient & 0.0 & 1.5 & \\
\hline
\end{tabular}

\subsection{ADR Incidence Rates}

As the same fixed dose of adalimumab $(40 \mathrm{mg})$ was subcutaneously administered to all patients [3], we investigated if BW may be the causative factor of the higher incidence rate of ADRs in women. To identify the factors that determined the ADRs induced by adalimumab, we examined the profile and incidence rates of ADRs by reviewing electronic charts and laboratory results, with particular attention to sex-related changes in ADR frequency in populations with different tiers of BW $(n=461)$ (Table 1). As expected, the overall incidence rate of ADRs was significantly higher in women than in men $(63.2 \%$ vs. $52.2 \%, p=0.019)$ (Table 1$)$. The average number of ADRs per patient (1.6) was the same for male and female patients as shown in Table 1. In addition, of all the conditions treated by adalimumab, the incidence of ADRs was significantly higher in female patients with ankylosing spondylitis than in corresponding male patients $(81.5 \%$ vs. $60.7 \%, p=0.041)$ (Table 1$)$. There were no statistically significant differences in other disease categories. For all listed conditions, there were no sex-based differences in pharmacological effects.

For patients with a record of initial BW while starting adalimumab prescription therapy, the incidence of ADRs was compared with regard to different BW subgroups (Method 2 in Figure 1). When we compared the ADR frequencies in the subgroup of the patients with lower $50 \%$ of BW, the proportion of patients experiencing ADRs was greater in female patients than in male patients (i.e., $68.0 \%$ vs. $54.5 \%, p=0.038$ ). However, there was no sex-related difference in the subgroup of the patients with upper $50 \%$ of BW (58.3\% vs. $50.0 \%, p=0.211$ ) (Table S2).

According to Method 1 in Figure 1, when we used the median female BW $(54.0 \mathrm{~kg})$ as a cutoff value, the incidence of ADRs was significantly different between male and female patients with BW $\geq 54.0 \mathrm{~kg}(50.4 \%$ vs. $58.3 \%, p<0.001)$, and the incidence of ADRs was similar in male and female 
patients with BW $<54.0 \mathrm{~kg}(66.7 \%$ vs. $68.0 \%, p=0.888)$ (Table 2). However, for both the sexes, ADR incidence in patients with $\mathrm{BW}<54.0 \mathrm{~kg}$ was significantly higher than that in patients with $\mathrm{BW} \geq 54.0$ $\mathrm{kg}(66.7 \%$ vs. $50.4 \%, p=0.068$ in male patients; and $68.0 \%$ vs. $58.3 \%, p=0.162$ in female patients) (Table 2). Thus, both male and female patients with BW lower than the median female BW displayed a greater incidence of ADRs. Therefore, it is highly likely that the predominance of ADRs in female patients may result from their relatively lower BW, indicating the importance of $\mathrm{BW}$ as a determining factor of ADR occurrences.

Table 2. ADR incidence rates in subgroups divided by the cutoff of female median body weight (BW) (54 kg).

\begin{tabular}{|c|c|c|c|}
\hline & Males & Females & $p$-Values \\
\hline \multicolumn{4}{|l|}{$\mathrm{BW} \geq 54.0 \mathrm{~kg}(n=334)$} \\
\hline Number of Patients $(n,(\%))$ & $238(71.3 \%)$ & $96(28.7 \%)$ & \\
\hline Age (Median, $(\min -\max ))^{*}$ & $36(19-78)$ & $50.5(19-84)$ & $p=0.028$ \\
\hline BW (Median, (min-max)) & $67.5(54.0-120.0)$ & $59.8(54.0-80.0)$ & $p=0.215$ \\
\hline Effect, Yes $(n,(\%))$ & $209(87.8 \%)$ & $78(81.3 \%)$ & $p=0.118$ \\
\hline Number of Patients with ADRs $(n,(\%)) *$ & $120(50.4 \%)$ & $56(58.3 \%)$ & $p<0.001$ \\
\hline $\begin{array}{c}\text { ADR Cases per Patient } \\
\text { (Incidences/Number of Patients with ADR) }\end{array}$ & 1.56 & 1.66 & $p=0.470$ \\
\hline \multicolumn{4}{|l|}{$\mathrm{BW}<54.0 \mathrm{~kg}(n=127)$} \\
\hline Number of Patients $(n,(\%))$ & $30(23.6 \%)$ & $97(76.4 \%)$ & \\
\hline Age (Median, (min-max)) & $30.5(20-78)$ & $47(19-79)$ & $p=0.271$ \\
\hline BW (Median, (min-max)) & $49.7(36.8-53.5)$ & $49.0(31.7-53.9)$ & $p=0.358$ \\
\hline Effect, Yes $(n,(\%))$ & $24(80.0 \%)$ & $78(80.4 \%)$ & $p=0.960$ \\
\hline Number of Patients with ADRs $(n,(\%))$ & $20(66.7 \%)$ & $66(68.0 \%)$ & $p=0.888$ \\
\hline $\begin{array}{c}\text { ADR Cases per Patient } \\
\text { (Incidences/Number of Patients with ADR) }\end{array}$ & 1.75 & 1.61 & $p=0.586$ \\
\hline
\end{tabular}

${ }^{*}$ Items marked are statistically significant for gender differences.

The median BW of all patients examined in this study was approximately $60.0 \mathrm{~kg}$. When we compared ADR frequencies in the subgroups of patients with different $B W$, we found that subgroups of both male and female patients with a BW $<60.0 \mathrm{~kg}$ showed BW-dependent frequencies of ADR, with an inverse correlation $\left(\mathrm{a}=-0.9441, \mathrm{r}^{2}=0.8418\right)$ (Figure 2A). The correlation between ADR frequency and BW did not exist in patients with $B W \geq 60.0 \mathrm{~kg}\left(\mathrm{a}=-0.0471, \mathrm{r}^{2}=0.0043\right)$ (Figure 2B). Thus, it appears that both male and female patients with a BW of $60.0 \mathrm{~kg}$ may be more vulnerable to ADRs induced by adalimumab injections.

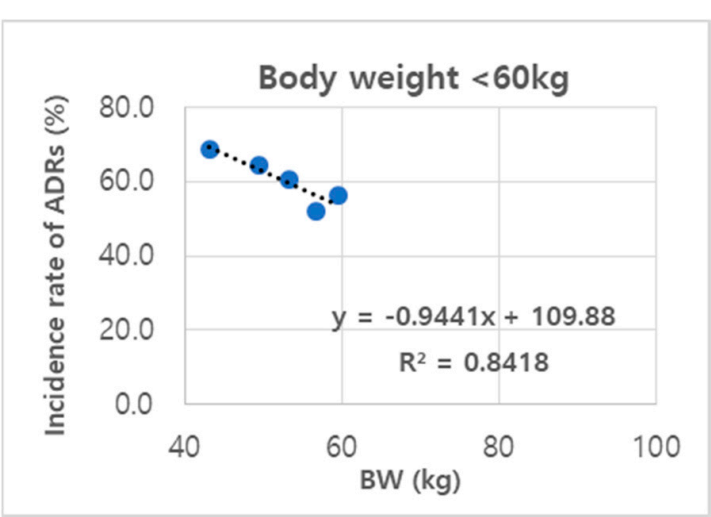

(A)

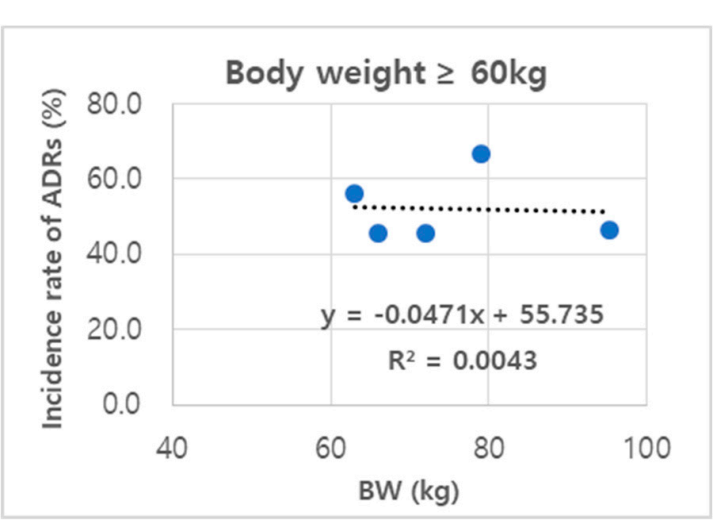

(B)

Figure 2. ADR incidence rates in subgroups tiered by BW. (A) Male and female patients with a BW < $60.0 \mathrm{~kg}$ and (B) Male and female patients with a $\mathrm{BW} \geq 60.0 \mathrm{~kg}$. 


\subsection{ADR Types}

The ADRs of adalimumab identified in the present study included infections (i.e., uvenitis, rhinitis, pneumonia, tuberculosis, virus infection, and fungus infection), pain, abnormal lab tests, mental/mood changes, and skin and gastrointestinal tract problems. Infections and dermatological problems were more prevalent than other ADRs (Table 3). A significantly higher frequency of skin problems and insomnia (psychiatrics) was noted in female patients than in male patients $(31.1 \%$ vs. $22.0 \%, p=0.03$ and $5.0 \%$ vs. $1.5 \%, p=0.012$, respectively). In particular, more female patients with ankylosing spondylitis reported skin problems (Table 3). Among patients with Bechet's disease or Crohn's disease, abnormal lab tests were more common in female patients (Table 3).

Table 3. Types of ADRs in male or female patients with different diseases.

\begin{tabular}{|c|c|c|c|c|}
\hline Types of ADRs & & Male & Female & $p$-Value \\
\hline Total Number of Patients $(n=461)(n,(\%))$ & & $268(58.1 \%)$ & $193(41.9 \%)$ & \\
\hline Infection $(n,(\%))$ & & $59(22.0 \%)$ & $44(22.8 \%)$ & $p=0.768$ \\
\hline Pain $(n,(\%))$ & & $18(6.7 \%)$ & $16(8.3 \%)$ & $p=0.993$ \\
\hline \multirow{2}{*}{ Dermatologicals $(n,(\%))$} & Skin * & $59(22.0 \%)$ & $60(31.1 \%)$ & $p=0.030$ \\
\hline & Alopecia & $5(1.9 \%)$ & $7(3.6 \%)$ & $p=0.374$ \\
\hline Gastrointestinals $(n,(\%))$ & & $26(9.7 \%)$ & $17(8.8 \%)$ & $p=0.473$ \\
\hline Psychiatrics $(n,(\%)) *$ & & $4(1.5 \%)$ & $11(5.0 \%)$ & $p=0.012$ \\
\hline Abnormal Lab Test $(n,(\%))$ & & $32(12.0 \%)$ & $30(15.6 \%)$ & $p=0.625$ \\
\hline Others $(n,(\%))$ & & $19(7.1 \%)$ & $14(7.3 \%)$ & $p=0.946$ \\
\hline \multicolumn{5}{|l|}{ (1) Ankylosing Spondylitis (A) } \\
\hline Number of Patients $(n=149)(n,(\%))$ & & $122(81.9 \%)$ & $27(18.1 \%)$ & \\
\hline Infection $(n,(\%))$ & & $33(27.0 \%)$ & $8(29.6 \%)$ & $p=0.786$ \\
\hline Pain $(n,(\%))$ & & $9(7.4 \%)$ & $5(18.5 \%)$ & $p=0.073$ \\
\hline \multirow{2}{*}{ Dermatologicals $(n,(\%))$} & Skin * & $32(26.2 \%)$ & $13(48.1 \%)$ & $p=0.025$ \\
\hline & Alopecia & $2(1.6 \%)$ & $0(0.0 \%)$ & $p=0.503$ \\
\hline Gastrointestinals $(n,(\%))$ & & $20(16.4 \%)$ & $3(11.1 \%)$ & $p=0.492$ \\
\hline Psychiatrics $(n,(\%))$ & & $4(3.3 \%)$ & $3(1.6 \%)$ & $p=0.082$ \\
\hline Abnormal Lab Test $(n,(\%))$ & & $17(14.0 \%)$ & $7(25.9 \%)$ & $p=0.125$ \\
\hline Others $(n,(\%)) *$ & & $5(4.1 \%)$ & $4(14.8 \%)$ & $p=0.034$ \\
\hline \multicolumn{5}{|l|}{ (2) Rheumatoid Arthritis (R) } \\
\hline Number of Patients $(n=125)(n,(\%))$ & & $38(30.4 \%)$ & $87(69.6 \%)$ & \\
\hline Infection $(n,(\%))$ & & $9(23.7 \%)$ & $19(21.8 \%)$ & $p=0.820$ \\
\hline Pain $(n,(\%))$ & & $4(10.5 \%)$ & $7(8.0 \%)$ & $p=0.653$ \\
\hline \multirow{2}{*}{ Dermatologicals $(n,(\%))$} & Skin & $8(21.1 \%)$ & $22(25.3 \%)$ & $p=0.481$ \\
\hline & Alopecia & $1(2.6 \%)$ & $4(4.6 \%)$ & $p=0.873$ \\
\hline Gastrointestinals $(n,(\%))$ & & $4(10.5 \%)$ & $8(9.2 \%)$ & $p=0.816$ \\
\hline Psychiatrics $(n,(\%))$ & & $0(0.0 \%)$ & $5(1.1 \%)$ & $p=0.131$ \\
\hline Abnormal Lab Test $(n,(\%))$ & & $3(7.9 \%)$ & $6(6.8 \%)$ & $p=0.843$ \\
\hline Others $(n,(\%))$ & & $6(15.8 \%)$ & $8(9.2 \%)$ & $p=0.389$ \\
\hline \multicolumn{5}{|l|}{ (3) Bechet's Disease Plus Crohn's Disease $(B+C)$} \\
\hline Subtotal $(n=144)(n,(\%))$ & & $91(63.2 \%)$ & $53(43.8 \%)$ & \\
\hline Infection $(n,(\%))$ & & $14(15.4 \%)$ & $11(20.8 \%)$ & $p=0.412$ \\
\hline Pain $(n,(\%))$ & & $4(4.4 \%)$ & $3(5.7 \%)$ & $p=0.426$ \\
\hline \multirow{2}{*}{ Dermatologicals $(n,(\%))$} & Skin & $15(16.5 \%)$ & $15(28.3 \%)$ & $p=0.092$ \\
\hline & Alopecia & $1(1.1 \%)$ & $3(5.7 \%)$ & $p=0.108$ \\
\hline Gastrointestinals $(n,(\%))$ & & $2(2.2 \%)$ & $3(5.7 \%)$ & $p=0.274$ \\
\hline Psychiatrics $(n,(\%))$ & & $0(0.0 \%)$ & $2(3.8 \%)$ & $p=0.062$ \\
\hline Abnormal Lab Test $(n,(\%))^{*}$ & & $10(11.0 \%)$ & $14(26.4 \%)$ & $p=0.017$ \\
\hline Others $(n,(\%))$ & & $5(5.5 \%)$ & $1(1.9 \%)$ & $p=0.296$ \\
\hline
\end{tabular}


Table 3. Cont.

\begin{tabular}{|c|c|c|c|c|}
\hline Types of ADRs & & Male & Female & $p$-Value \\
\hline \multicolumn{5}{|l|}{ (4) Psoriasis (P) } \\
\hline Subtotal $(n=15)(n,(\%))$ & & $8(53.3 \%)$ & $7(46.7 \%)$ & \\
\hline Infection $(\mathrm{n},(\%))$ & & $2(25.0 \%)$ & $2(28.6 \%)$ & $p=0.876$ \\
\hline Pain $(n,(\%))$ & & $0(0.0 \%)$ & $0(0.0 \%)$ & - \\
\hline \multirow{2}{*}{ Dermatologicals $(n,(\%))$} & Skin & $1(12.5 \%)$ & $3(42.9 \%)$ & $p=0.185$ \\
\hline & Alopecia & $1(12.5 \%)$ & $0(0.0 \%)$ & $p=0.333$ \\
\hline Gastrointestinals $(n,(\%))$ & & $0(0.0 \%)$ & $2(28.6 \%)$ & $p=0.104$ \\
\hline Psychiatrics $(n,(\%))$ & & $0(0.0 \%)$ & $1(14.3 \%)$ & $p=0.268$ \\
\hline Abnormal Lab Test $(n,(\%))$ & & $1(12.5 \%)$ & $2(28.6 \%)$ & $p=0.438$ \\
\hline Others $(n,(\%))$ & & $1(12.5 \%)$ & $0(0.0 \%)$ & $p=0.333$ \\
\hline \multicolumn{5}{|c|}{$\begin{array}{c}\text { (5) Two or More Other Diseases (Comorbid } \\
\text { Diseases) }\end{array}$} \\
\hline Subtotal $(n=17)(n,(\%))$ & & $6(35.3 \%)$ & $11(64.7 \%)$ & \\
\hline Infection $(n,(\%))$ & & $1(16.7 \%)$ & $3(27.3 \%)$ & $p=0.159$ \\
\hline Pain $(n,(\%))$ & & $1(16.7 \%)$ & $1(9.1 \%)$ & $p=0.643$ \\
\hline \multirow{2}{*}{ Dermatologicals $(n,(\%))$} & Skin & $3(50.0 \%)$ & $7(63.6 \%)$ & $p=0.585$ \\
\hline & Alopecia & $0(0.0 \%)$ & $0(0.0 \%)$ & - \\
\hline Gastrointestinals $(n,(\%))$ & & $0(0.0 \%)$ & $0(0.0 \%)$ & - \\
\hline Psychiatrics $(n,(\%))$ & & $0(0.0 \%)$ & $0(0.0 \%)$ & - \\
\hline Abnormal Lab Test $(n, \%)$ & & $1(16.7 \%)$ & $1(9.1 \%)$ & $p=0.643$ \\
\hline Others $(n,(\%))^{*}$ & & $2(33.3 \%)$ & $0(0.0 \%)$ & $p=0.041$ \\
\hline \multicolumn{5}{|l|}{ (6) Others (E) } \\
\hline Subtotal $(n=11)(n,(\%))$ & & $3(27.3 \%)$ & $8(72.7 \%)$ & \\
\hline Infection $(n,(\%))$ & & $0(0.0 \%)$ & $1(12.5 \%)$ & $p=0.521$ \\
\hline Pain $(n,(\%))$ & & $0(0.0 \%)$ & $0(0.0 \%)$ & - \\
\hline \multirow{2}{*}{ Dermatologicals $(n,(\%))$} & Skin & $0(0.0 \%)$ & $0(0.0 \%)$ & - \\
\hline & Alopecia & $0(0.0 \%)$ & $0(0.0 \%)$ & - \\
\hline Gastrointestinals $(n,(\%))$ & & $0(0.0 \%)$ & $1(12.5 \%)$ & $p=0.521$ \\
\hline Psychiatrics $(n,(\%))$ & & $0(0.0 \%)$ & $0(0.0 \%)$ & - \\
\hline Abnormal Lab Test $(n,(\%))$ & & $0(0.0 \%)$ & $0(0.0 \%)$ & - \\
\hline Others $(n,(\%))$ & & $0(0.0 \%)$ & $1(12.5 \%)$ & $p=0.521$ \\
\hline
\end{tabular}

\section{Discussion}

Recognizing ADRs has emerged as a key factor in deciding an appropriate medication therapy for a particular condition. As adverse reactions and toxicities of drugs may vary depending on sex, information on ADRs should provide incidence rates, severity, durations, and onset times of parameters of interest in both the sexes. ADRs induced by drugs may vary between the sexes owing to differences in height, weight, pharmacokinetics, and genetic characteristics $[16,17]$. However, many previous studies mostly have included men [18,19]. In general, the medication guidelines, systems, and policies that specify sex differences appear to be incomplete. We first examined a 10-year period of voluntary ADR reports archived in the Korean Institute of Drug Safety and Risk Management and extracted drug items that led to potential differences in the occurrence of ADRs based on sex. However, as these archives included only voluntary reports, it was not plausible to estimate the overall proportion and incidence rate. Thus, the present study utilized an EMR database to analyze the incidence, type, and severity of ADRs induced by adalimumab.

Adalimumab is administered to adults as a 40-mg solution for injection in a pre-filled syringe. In the context of patient $\mathrm{BW}$, the dose is only adjusted for patients with polyarticular juvenile idiopathic arthritis or with plaque psoriasis. The recommended dosing regimen is $20 \mathrm{mg}$ every other week for patients with a BW of $10.0 \mathrm{~kg}$ to $<30.0 \mathrm{~kg}$ and $40 \mathrm{mg}$ every other week for those with a BW of 
$\geq 30.0 \mathrm{~kg}$. The available data suggest that clinical response is usually achieved within 12 weeks of treatment [20]. If patients do not exhibit a response during this period, continued therapy should be reconsidered [21]. The dose of adalimumab for pediatric patients with Crohn's disease is also based on BW. The induction dose is $80 \mathrm{mg}$ during week 0 and $40 \mathrm{mg}$ during week 2 for patients with a BW of $<40.0 \mathrm{~kg}$, if there is a need for a more rapid response to therapy, and with the awareness that the risk of adverse events may be higher with use of a higher induction dose (a maintenance dose of $20 \mathrm{mg}$ every other week is recommended). For patients with a BW of $\geq 40.0 \mathrm{~kg}$, the doses are doubled (i.e., $160 \mathrm{mg}$ during week 0 and $80 \mathrm{mg}$ during week 2) [22]. Hence, the regular dose of adalimumab for adults with inflammatory diseases is usually $40 \mathrm{mg}$ per patient, regardless of the sex and BW. The prescription rate of adalimumab has gradually increased since its introduction in the market [22,23], and there will be several more adalimumab biosimilars available in the future [23,24].

In the study of Lesuis et al. [25], the proportion of rheumatoid arthritis in patients was higher in women and rates of inflammatory bowel disease and psoriasis were higher in men [25]. In the present study, rheumatoid arthritis was also more common in women but rates of inflammatory bowel disease and psoriasis were similar in men and women. In other studies, female sex has been reported as a predictor for biological discontinuation of adalimumab in the treatment of psoriasis [26], rheumatoid arthritis, and axial spondyloarthritis [27]. The incidence of ADRs induced by adalimumab was greater in female patients, although the types of adverse reactions were different [28]. Therefore, among the non-responders, the discontinuation rate of adalimumab was higher in female patients [28,29].

An important finding of our study was the identification of BW as a factor that determines the predominance of ADRs in female patients. This idea was supported by the different frequencies of ADRs in the analysis of subgroups based on BW tiers in male and female patients. The frequency of ADRs in either male or female patients with a BW of $<60.0 \mathrm{~kg}$ exhibited BW dependency likely because the median BW was significantly lower in female patients than in male patients (the proportion of female patients with a BW of $<60.0 \mathrm{~kg}$ was $68.0 \%$ ). Additionally, Hansel et al. [30] demonstrated the importance of BMI in determining a dosage regimen of adalimumab. Dose tapering with adalimumab was efficacious and safe, especially in patients with low BMI. These patients showed maintenance of efficacy and, in cases of relapse, only needed a short time to re-achieve disease clearance at a standard dose [30].

The incidence and characteristics of ADRs in the present study were similar to those in a study by Noah et al. [29]: 28.4\% patients in our study experienced dermatological problems (Table 3), which was similar to the $30 \%$ of patients with skin and allergenic reactions in the study by Noah et al. [31]. In another study, the percentage of ADRs in patients with rheumatoid arthritis followed for 3 years after the start of adalimumab treatment was 34.2\% [32]. In our study, the frequency of ADRs induced by adalimumab used to treat rheumatoid arthritis was 60.0\% (19 male patients and 56 female patients among a total of 125 patients) (Table 1). The difference might be attributed to our prolonged follow-up period (5.5 years). Adalimumab dose adjustment is usually done by controlling either the first dose or the maintenance dose and the dosing intervals [33]. After considering the long half-life of this drug, extending dosing intervals might be recommended for female patients to reduce ADRs because higher concentration of adalimumab might cause higher incidence of ADRs. As skin-related ADRs and insomnia were more prevalent in female patients, it is also necessary to monitor and educate the patients on these sex-based differences.

\section{Conclusions}

Collectively, our findings indicate that the incidence of ADRs induced by adalimumab therapy was higher in female patients, which may have been because of the difference in mean BW (i.e., a greater proportion of female patients had a lower BW) and the features of adalimumab injectable medication. This was consistent with the reported increase in the incidence of ADRs induced by adalimumab with a decrease in $\mathrm{BW}$, which occurs owing to increasing adalimumab concentrations due to the reduced elimination rate $[34,35]$. 
Supplementary Materials: The following are available online at http://www.mdpi.com/2077-0383/9/2/461/s1, Table S1: Demographic characteristics of all patients administered adalimumab; Table S2: Effectiveness and ADR incidences in male or female patients sub-grouped by 50 percentile.

Author Contributions: Conceptualization, K.S.K., A.M. and S.G.K.; methodology, K.S.K.; software, K.S.K. and Y.H.C.; formal analysis, Y.H.C and K.S.K.; investigation, K.S.K.; resources, K.S.K. and S.G.K.; data curation, K.S.K.; writing-original draft preparation, K.S.K., Y.H.C and S.G.K; writing—review and editing, Y.H.C and S.G.K.; supervision, S.G.K.; project administration, A.M. and S.G.K.; funding acquisition, A.M. and S.G.K. All authors have read and agreed to the published version of the manuscript.

Funding: This research was supported by the Education and Research Encouragement Fund of Seoul National University Hospital (SGK), and in part by the Bio \& Medical Technology Development Program (2015M3A9B6074045) of the National Research Foundation and the Support Program for Women in Science, Engineering and Technology through NRF (2019H1C3A 10322224) funded by the Korean government.

Conflicts of Interest: All authors declare no conflict of interest.

\section{References}

1. Lis, K.; Kuzawińska, O.; Bałkowiec-Iskra, E. Tumor necrosis factor inhibitors-state of knowledge. Arch. Med. Sci. 2014, 10, 1175-1185. [CrossRef]

2. Cassinotti, A.; Sandro, A.; Porro, G.B. Adalimumab for the treatment of Crohn's disease. Biologics 2008, 2, 763-777.

3. Burmester, G.R.; Gordon, K.B.; Rosenbaum, J.T.; Arikan, D.; Lau, W.; Li, P.; Faccin, F.; Panaccione, R. Long-term safety of adalimumab in 29,967 adult patients from global clinical trials across multiple indications: An updated analysis. Adv. Ther. 2020, 37, 364-380. [CrossRef] [PubMed]

4. FDA. Approval Package for BLA125057/S280/. Available online: https://www.accessdata.fda.gov/ drugsatfdadocs/bla/2010/125057Orig1s0213.pdf (accessed on 25 July 2019).

5. Datta, K.; Ghosh, R.K.; Ghosh, S.M. Serious neutropenia following etanercept administration in a 62 years female patient of rheumatoid arthritis. J. Assoc. Physicians India 2010, 58, 643-644. [PubMed]

6. Tayar, J.H.; Lopez-Olivo, M.A.; Suarez-Almazor, M.E. Adalimumab: 8 years of experience in rheumatoid arthritis. Int. J. Clin. Rheumatol. 2013, 8, 165-184. [CrossRef]

7. Chu, L.H.; Portugal, C.; Kawatkar, A.A.; Stohl, W.; Nichol, M.B. Racial/ethnic differences in the use of biologic disease-modifying antirheumatic drugs among California Medicaid rheumatoid arthritis patients. Arthritis Care Res. 2013, 65, 299-303. [CrossRef] [PubMed]

8. Lie, M.R.; Kreijne, J.E.; van der Woude, C.J. Sex is associated with adalimumab side effects and drug survival in patients with Crohn's disease. Inflamm. Bowel Dis. 2017, 23, 75-81. [CrossRef] [PubMed]

9. Vavricka, S.R.; Bentele, N.; Scharl, M.; Rogler, G.; Zeitz, J.; Frei, P.; Straumann, A.; Binek, J.; Schoepfer, A.M.; Fried, M.; et al. Systematic assessment of factors influencing preferences of Crohn's disease patients in selecting an anti-tumor necrosis factor agent (CHOOSE TNF Trial). Inflamm. Bowel Dis. 2012, 18, 1523-1530. [CrossRef] [PubMed]

10. Van der Valk, M.E.; Mangen, M.J.; Leenders, M.; Dijkstra, G.; van Bodegraven, A.A.; Fidder, H.H.; de Jong, D.J.; Pierik, M.; van der Woude, C.J.; Romberg-Camps, M.J.; et al. Healthcare costs of inflammatory bowel disease have shifted from hospitalization and surgery towards anti-TNF $\alpha$ therapy results from the COIN study. Gut 2014, 63, 72-79. [CrossRef]

11. Nakase, H.; Motoya, S.; Matsumoto, T.; Watanabe, K.; Hisamatsu, T.; Yoshimura, N.; Ishida, T.; Kato, S.; Nakagawa, T.; Esaki, M.; et al. Significance of measurement of serum trough level and anti-drug antibody of adalimumab as personalized pharmacokinetics in patients with Crohn's disease: A sub-analysis of the DIAMOND trial. Aliment. Pharmacol. Ther. 2017, 46, 873-882. [CrossRef]

12. Luzier, A.B.; Killian, A.; Wilton, J.H.; Wilson, M.F.; Forrest, A.; Kazierad, D.J. Gender related effects on metoprolol pharmacokinetics and pharmacodynamics in healthy volunteers. Clin. Pharmacol. Ther. 1999, 66, 594-601. [CrossRef] [PubMed]

13. Regitz-Zagrosek, V.; Seeland, U. Sex and gender differences in clinical medicine. In Sex and Gender Differences in Pharmacology; Springer: Berlin/Heidelberg, Germany, 2012; Volume 214, pp. 3-22.

14. Schmetzer, O.; Florcken, A. Sex differences in the drug therapy for oncologic diseases. In Sex and Gender Differences in Pharmacology; Springer: Berlin/Heidelberg, Germany, 2012; Volume 214, pp. 411-442. 
15. Islam, M.; Iqbal, U.; Walther, B.A.; Nguyen, P.-A.; Li, Y.-C.; Dubey, N.K.; Poly, T.N.; Masud, J.H.B.; Atique, S.; Syed-Abdul, S. Gender based personalized pharmacotherapy: A systemic review. Arch. Gynecol. Obstet. 2017, 295, 1305-1317. [CrossRef] [PubMed]

16. Soldin, O.P.; Mattison, D.R. Sex differences in pharmacokinetics and pharmacodynamics. Clin. Pharmacokinet. 2009, 49, 143-157. [CrossRef] [PubMed]

17. Amderson, G.D. Gender differences in pharmacological response. Int. Rev. Neurobiol. 2008, 83, 1-10.

18. Panaccione, R.; Loftus, E.V.; Binion, D.; McHugh, K.; Alam, S.; Chen, N.; Guerette, B.; Mulani, P.; Chao, J. Efficacy and safety of adalimumab in Canadian patients with moderate to severe Crohn's disease: Results of the adalimumab in Canadian subjects with moderate to severe Crohn's disease (ACCESS) trial. Can. J. Gastroenterol. 2011, 25, 419-425. [CrossRef]

19. Bartley, E.J.; Fillingim, R.B. Sex differences in pain: A brief review of clinical and experimental finding. Br. J. Anaesth. 2013, 111, 52-58. [CrossRef]

20. Peters, C.P.; Eshuis, E.J.; Toxopeüs, F.M.; Hellemons, M.E.; Jansen, J.M.; D’Haens, G.R.; Fockens, P.; Stokkers, P.C.; Tuynman, H.A.; van Bodegraven, A.A.; et al. Adalimumab for Crohn's disease: Long-term sustained benefit in a population-based cohort of 438 patients. J. Crohn's Colitis 2014, 8, 766-775. [CrossRef]

21. National Institute for Health and Care Excellence. Infliximab and Adalimumab for Crohn's Disease. Technology Appraisal Guidance. (Published Date: 19 May 2010). Available online: https://www.nice.org.uk/ guidance/TA187 (accessed on 25 July 2019).

22. Sato, E.; Tanaka, E.; Ochiai, M.; Shimizu, Y.; Kobayashi, A.; Shidara, K.; Hoshi, D.; Sugimoto, N.; Inoue, E.; Seto, Y.; et al. Chronological changes in baseline disease activity of patients with rheumatoid arthritis who received biologic DMARDs between 2003 and 2012. Mod. Rheumatol. 2015, 25, 350-357. [CrossRef]

23. Fiorino, G.; Gilardi, D.; Correale, C.; Furfaro, F.; Roda, G.; Loy, L.; Argollo, M.; Allocca, M.; Peyrin-Biroulet, L.; Danese, S. Biosimilars of adalimumab: The upcoming challenge in IBD. Expert Opin. Biol. Ther. 2019, 19, 1023-1030. [CrossRef]

24. Severs, M.; Oldenburg, B.; van Bodegraven, A.A.; Siersema, P.D.; Mangen, M.J.; Initiative of Crohn's and Colitis. The economic impact of the introduction of biosimilars in inflammatory bowel disease. J. Crohn's Colitis 2017, 11, 289-296. [CrossRef]

25. Lesuis, N.; Befrits, R.; Nyberg, F.; van Vollenhoven, R.F. Gender and the treatment of immune mediated chronic inflammatory diseases: Rheumatoid arthritis, inflammatory bowel disease and psoriasis: An observational study. BMC Med. 2012, 10, 82. [CrossRef]

26. Lin, P.T.; Wang, S.H.; Chi, C.C. Drug survival of biologics in treating psoriasis: A meta-analysis of real-world evidence. Sci. Rep. 2018, 8, 16068. [CrossRef] [PubMed]

27. Rusman, T.; van Vollenhoven, R.F.; van der Horst-Bruinsma, I.E. Gender differences in axial spondyloarthritis: Women are not so lucky. Curr. Rheumatol. Rep. 2018, 20,35. [CrossRef] [PubMed]

28. Zelinkova, Z.; Bultman, E.; Vogelaar, L.; Bouziane, C.; Kuipers, E.J.; van der Woude, C.J. Sex-dimorphic adverse drug reactions to immune suppressive agents in inflammatory bowel disease. World J. Gastroenterol. 2012, 18, 6967-6973. [CrossRef] [PubMed]

29. Panaccione, R.; Sandborn, W.J.; D’Haens, G.; Wolf, D.C.; Berg, S.; Maa, J.F.; Petersson, J.; Robinson, A.M. Clinical benefit of long-term adalimumab treatment in patients with Crohn's disease following loss of response or intolerance to infliximab: 96-week efficacy data from GAIN/ADHERE Trials. J. Crohn's Colitis 2018, 12, 930-938. [CrossRef]

30. Hansel, K.; Bianchi, L.; Lanza, F.; Bini, V.; Stingeni, L. Adalimumab dose tapering in psoriasis: Predictive factors for maintenance of complete clearance. Acta Derm. Venereol. 2017, 97, 346-350. [CrossRef]

31. Scheinfeld, N. Adalimumab: A review of side effect. Expert Opin. Drug Saf. 2005, 4, 637-641. [CrossRef]

32. Harigai, M.; Tsuchiya, T.; Kawana, K.; Kurimoto, S. Long-term safety and effectiveness of adalimumab for the treatment of Japanese patients with rheumatoid arthritis: 3-year results from a postmarketing surveillance of 552 patients. Mod. Rheumatol. 2008, 28, 30-38. [CrossRef]

33. Chao, Y.S.; Visintini, S. Biologics Dose Escalation for the Treatment of Inflammatory Bowel Disease: A Review of Clinical Effectiveness, Cost-effectiveness and Guidelines. 2018. Available online: http: //creativecommons.org/licenses/by-nc-nd/4.0 (accessed on 25 July 2019). 
34. Humira (Adalimumab) Package Insert; AbbVie Inc.: North Chicago, IL, USA, 2013; Available online: https: //www.humira.com (accessed on 25 July 2019).

35. Hojgaard, P.; Blintgorg, B.; Kristensen, L.E.; Budbjornsson, B.; Love, T.J.; Dreyer, L. The influence of obesity on response to tumour necrosis factor- $\alpha$ inhibitors in psoriatic arthritis: Results from the DANBIO and ICEBIO registries. Rheumatology 2016, 55, 2191-2199. [CrossRef] 